\title{
Calcium Sensitization Mechanisms in Gastrointestinal Smooth Muscles
}

\author{
Brian A Perrino \\ Department of Physiology and Cell Biology, University of Nevada School of Medicine, Reno, NV, USA
}

An increase in intracellular $\mathrm{Ca}^{2+}$ is the primary trigger of contraction of gastrointestinal $(\mathrm{Gl})$ smooth muscles. However, increasing the $\mathrm{Ca}^{2+}$ sensitivity of the myofilaments by elevating myosin light chain phosphorylation also plays an essential role. Inhibiting myosin light chain phosphatase activity with protein kinase C-potentiated phosphatase inhibitor protein-17 kDa (CPI-17) and myosin phosphatase targeting subunit 1 (MYPT1) phosphorylation is considered to be the primary mechanism underlying myofilament $\mathrm{Ca}^{2+}$ sensitization. The relative importance of $\mathrm{Ca}^{2+}$ sensitization mechanisms to the diverse patterns of $\mathrm{Gl}$ motility is likely related to the varied functional roles of GI smooth muscles. Increases in CPI-17 and MYPT1 phosphorylation in response to agonist stimulation regulate myosin light chain phosphatase activity in phasic, tonic, and sphincteric GI smooth muscles. Recent evidence suggests that MYPT1 phosphorylation may also contribute to force generation by reorganization of the actin cytoskeleton. The mechanisms responsible for maintaining constitutive CPI-17 and MYPT1 phosphorylation in Gl smooth muscles are still largely unknown. The characteristics of the cell-types comprising the neuroeffector junction lead to fundamental differences between the effects of exogenous agonists and endogenous neurotransmitters on $\mathrm{Ca}^{2+}$ sensitization mechanisms. The contribution of various cell-types within the tunica muscularis to the motor responses of $\mathrm{Gl}$ organs to neurotransmission must be considered when determining the mechanisms by which $\mathrm{Ca}^{2+}$ sensitization pathways are activated. The signaling pathways regulating $\mathrm{Ca}^{2+}$ sensitization may provide novel therapeutic strategies for controlling GI motility. This article will provide an overview of the current understanding of the biochemical basis for the regulation of $\mathrm{Ca}^{2+}$ sensitization, while also discussing the functional importance to different smooth muscles of the Gl tract.

(J Neurogastroenterol Motil 2016;22:213-225)

Key Words

Gastrointestinal motility; Myosin-light-chain phosphatase; Phosphorylation; Signal transduction; Smooth muscle

\section{Introduction}

Contraction of gastrointestinal (GI) smooth muscles is primarily regulated by the intracellular $\mathrm{Ca}^{2+}$ signal. Excitatory contractile agonists elevate the cytosolic $\mathrm{Ca}^{2+}$ concentration $\left(\left[\mathrm{Ca}^{2+}\right]_{\mathrm{i}}\right)$ by triggering $\mathrm{Ca}^{2+}$ influx from the extracellular space, by activating $\mathrm{L}$ type $\mathrm{Ca}^{2+}$ channels and non-selective cation currents, along with
$\mathrm{Ca}^{2+}$ release from intracellular stores. The elevation of $\left[\mathrm{Ca}^{2+}\right]_{i}$ increases $\mathrm{Ca}^{2+}$-bound calmodulin, activating myosin light chain kinase (MLCK), which then phosphorylates the 20-kDa regulatory myosin light chain (MLC) at S19, stimulating myosin ATPase activity, and thereby activating cross-bridge cycling and contraction. ${ }^{2-5}$ Termination of the contractile stimulus leads to a decrease in $\left[\mathrm{Ca}^{2+}\right]_{\mathrm{i}}$, thereby decreasing MLCK activity. Consequently, MLC is dephosphorylated by the action of myosin light chain

Received: November 28, 2015 Revised: None Accepted: December 22, 2015

() This is an Open Access article distributed under the terms of the Creative Commons Attribution Non-Commercial License (http://creativecommons. org/licenses/by-nc/4.0) which permits unrestricted non-commercial use, distribution, and reproduction in any medium, provided the original work is properly cited.

*Correspondence: Brian A Perrino, PhD Department of Physiology and Cell Biology, University of Nevada School of Medicine, MS 0575, 1664 N Virginia St., Reno, NV 89557, USA

Tel: +1-775-784-6396, Fax: +1-775-784-6903, E-mail: bperrino@medicine.nevada.edu 
phosphatase (MLCP). ${ }^{6,7}$ The reversible phosphorylation of MLC thus plays a central role in the regulation of the contractile responses of GI smooth muscles. However, it is also well known that the relationship between the extent of the $\left[\mathrm{Ca}^{2+}\right]_{\mathrm{i}}$ elevation and the strength of the developed tension varies depending on the stimulus. ${ }^{5,89} \mathrm{In}$ general, receptor-mediated contractile stimuli produce more tension for a given elevation of $\left[\mathrm{Ca}^{2+}\right]_{\mathrm{i}}$ than membrane depolarization alone. ${ }^{10-13}$ The $\mathrm{Ca}^{2+}$-tension relationship also changes during the time course of the contraction, with the sustained phase of the contraction maintained by a relatively lower level of $\left[\mathrm{Ca}^{2+}\right]_{\mathrm{i}}{ }^{14}$ Phasic, tonic, and sphincter GI smooth muscles thus also exhibit different $\mathrm{Ca}^{2+}$-tension relationships that reflect their different functional contractile behaviors. ${ }^{15-17}$ Biochemically, the $\mathrm{Ca}^{2+}$-tension relationship is altered by adjusting the balance between MLCK and MLCP activities to increase or decrease MLC phosphorylation. ${ }^{5,18,19}$ Inhibiting MLCP while activating MLCK further tilts the balance toward MLCK, generating "extra" force by further increasing MLC phosphorylation. Since more force is generated at a given $\mathrm{Ca}^{2+}$ concentration, this phenomenon was termed " $\mathrm{Ca}^{2+}$ sensitization of the contractile apparatus," to refer to the apparent increase in $\mathrm{Ca}^{2+}$ sensitivity of the contractile response. ${ }^{18}$ The activity of MLCP is the key determinant of myofilament $\mathrm{Ca}^{2+}$ sensitization and is regulated by upstream signaling pathways. ${ }^{20,21}$ Once thought to only constitutively reverse MLC S19 phosphorylation by MLCK, MLCP is now known to function as a signal processor under complex regulatory control. ${ }^{20,22}$ Inhibition of MLCP activity and generation of $\mathrm{Ca}^{2+}$ sensitization can be mediated directly by phosphorylation of the myosin phosphatase targeting subunit 1 of MLCP (MYPT1) and/or indirectly by phosphorylation of a protein kinase C (PKC)potentiated phosphatase inhibitor protein-17 kDa (CPI-17). ${ }^{23,24}$ Although several possible phosphorylation sites on MYPT1 have been reported, the T696 and T853 sites (numbering of the human isoform) are the most extensively studied and have been confirmed to be important for the inhibition of MLCP activity. ${ }^{5,25,26}$ Likewise, phosphorylation of CPI-17 at T38 is the most extensively studied and can potentiate its inhibition of MLCP. ${ }^{27}$ As a result, similar to other smooth muscles, the contraction of GI smooth muscles is subject to dual regulation by the $\mathrm{Ca}^{2+}$ signal and alteration of the $\mathrm{Ca}^{2+}$ sensitivity of the contractile apparatus (Figure). Investigations during the last several years have revealed the details of the biochemical basis for the regulation and functional roles of $\mathrm{Ca}^{2+}$ sensitization mechanisms in GI smooth muscles. However, due to the variety of different approaches, smooth muscle types, and animal models utilized in such studies, there is still an incomplete understanding

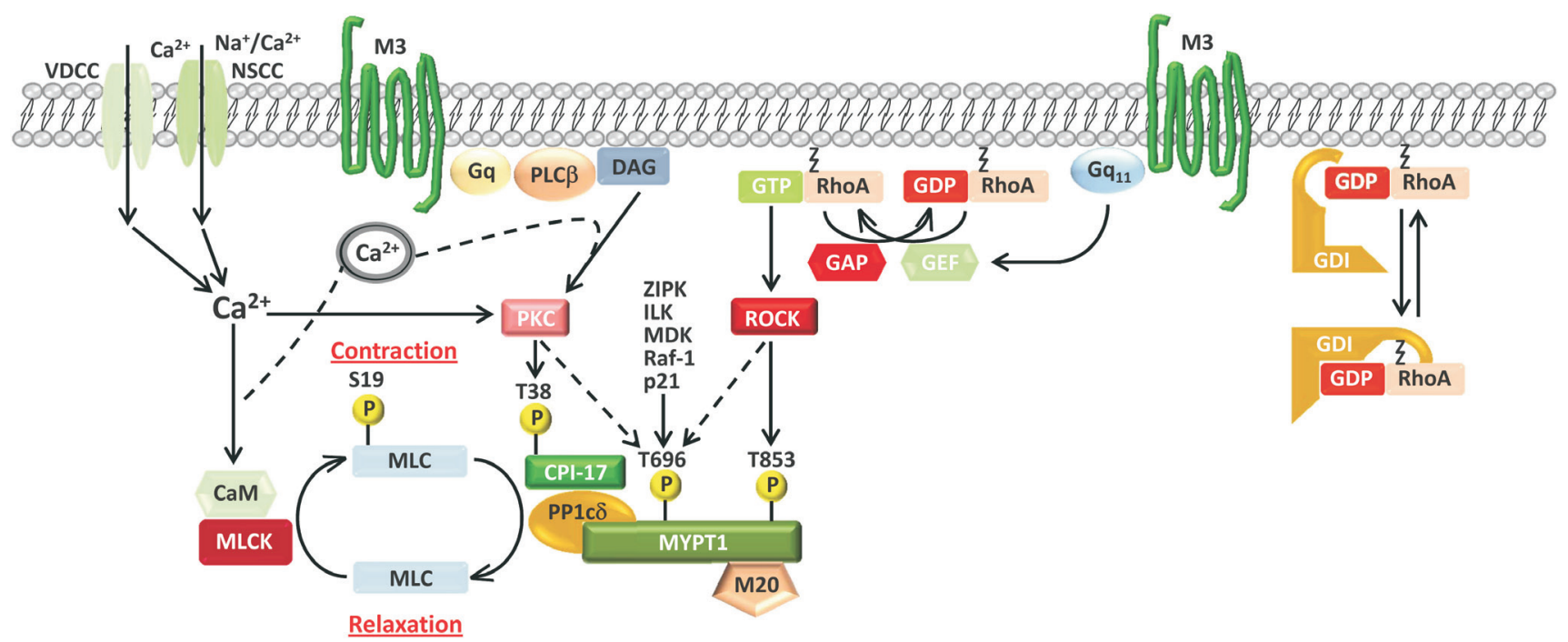

Figure. Regulating the level of myosin light chain (MLC) phosphorylation, and smooth muscle contractility, by regulating myosin light chain phosphatase (MLCP) activity. Reduced MLCP activity relative to myosin light chain kinase (MLCK) activity favors increased MLC phosphorylation, potentiating contractile responses. The major kinase pathways targeting MLCP activity with inhibitory phosphorylations are depicted. Stimuli (from voltage-dependent $\mathrm{Ca}^{2+}$ channels [VDCC]) or non-selective cation currents (NSCC) that increase cytosolic $\mathrm{Ca}^{2+}$ activate a protein kinase C (PKC) and phosphorylation of CPI-17 at T38. PKC and several other kinases can phosphorylate myosin phosphatase targeting subunit 1 (MYPT1) at T696. Stimuli (from G protein coupled receptor activation) increase GTP-RhoA levels via activation of RhoA guanine nucleotide exchange factors (GEFs), resulting in Rho-associated, coiled-coil containing protein kinase (ROCK) activation and phosphorylation of MYPT1 at T853. The regulation of GTP-RhoA by guanine nucleotide dissociation inhibitor (GDI), GEFs, and GTPase activating proteins (GAPs) is included. 
of the relative contribution of $\mathrm{Ca}^{2+}$ sensitization mechanisms to the motor behaviors of GI smooth muscles. One thing that is clear is that there are a variety of mechanisms that can alter the $\mathrm{Ca}^{2+}$ sensitivity of GI smooth muscles which converge on regulating the activity of MLCP. Thus, similar to other smooth muscles, the regulation of MLCP activity plays a central role in the mechanisms eliciting $\mathrm{Ca}^{2+}$ sensitization in GI smooth muscles. However, additional mechanisms affecting the $\mathrm{Ca}^{2+}$ sensitivity of contraction are being revealed, that likely contribute to the functional responses of GI smooth muscles. In this review article, I would like to summarize the current understanding of the mechanisms regulating MLCP activity, as well as MLCP- and myofilament-independent mechanisms, and then discuss their physiological relevance to the regulation of $\mathrm{Ca}^{2+}$ sensitivity and contractile responses of GI smooth muscles.

\section{Myosin Light Chain Phosphatase Structure and Regulation}

MLCP is a heterotrimeric holoenzyme composed of the 38 $\mathrm{kDa}$ catalytic subunit of type 1 protein phosphatase (PPP1C, $\delta$ isoform), and the $110 \mathrm{kDa}$ and $20 \mathrm{kDa}$ non-catalytic subunits. ${ }^{21,28,29}$ The free catalytic subunit of PPP1C displays broad substrate specificity in vitro. ${ }^{30}$ Thus PPP1C in vivo is typically found in a complex with different proteins (termed PPP1C-binding proteins, PBPs) which confer different substrate specificities to PPP1C. ${ }^{30} \mathrm{PBPs}$ allosterically alter the substrate specificity of PPP1C through proteinprotein interactions and by localizing $\mathrm{PPP} 1 \mathrm{C}$ in close proximity to the desired substrate. ${ }^{31,32}$ Both mechanisms, which are not mutually exclusive, can increase the rate of substrate dephosphorylation by up to several orders of magnitude. ${ }^{33}$ The $110 \mathrm{kDa}$ PBP subunit binds to myosin, targeting PPP1C to myosin filaments, and is referred to as the myosin phosphatase targeting subunit (MYPT). ${ }^{34,35}$ There are several isoforms of MYPT, but MYPT1 (PPP1R12A) is the major isoform expressed in GI smooth muscle. ${ }^{25}$ In addition to targeting PPP1C $\delta$ to myosin filaments, MYPT1 increases the substrate specificity of PPP $1 \mathrm{C} \delta$ toward myosin, and, through its phosphorylation status, regulates the enzymatic activity of PPP1C $\delta .^{21,25}$ There are also splice variants of MYPT1, in which the leucine zipper $(\mathrm{LZ})$ motifs are either present $(\mathrm{LZ}+)$ or absent (LZ-). ${ }^{36}$ The relative expression levels of $\mathrm{LZ}+$ and LZ- MYPT1 isoforms are an important determinant of the sensitivity of smooth muscles to nitric oxide. ${ }^{37,38}$ The LZ domain has been demonstrated to be required for cGMP-dependent protein kinase to phosphorylate MYPT1 at S668 and increase MLCP activity. ${ }^{39-41}$ MYPT1 thus plays a critical role in the regulation of MLCP activity and smooth muscle excitability. The $20 \mathrm{kDa}$ subunit, referred to as smM20 (PPP1R12B), binds to the $C$-terminal region of MYPT1. The sequence of M20 resembles the $C$-terminal region of MYPT1 and contains 3 leucine zippers. ${ }^{42}$ A smaller splice variant of M20 lacks the leucine zippers. ${ }^{35}$ Although the functional role of M20 is still not clear, the heart-specific small subunit of MLCP (HSM21) was shown to increase the $\mathrm{Ca}^{2+}$ sensitivity of contraction of permeabilized renal arterial smooth muscle and cardiomyocytes, and increase the $\mathrm{Ca}^{2+}$ sensitivity of cardiac muscle contraction. ${ }^{43,44}$

\section{Relative Importance of MYPT1 and CPI-17 to the Regulation of Myosin Light Chain Phosphorylation by $\mathrm{Ca}^{2+}$ Sensitization Mechanisms}

Changes in MLC phosphorylation are due to net changes in the activities of MLCK and MLCP relative to each other. Thus, the expression levels of MYPT1 and CPI-17 relative to MLCK and MLC are a factor in evaluating their relative importance to the regulation of MLCP activity within a particular smooth muscle tissue. The expression level of MYPT1 can be used as an indicator of the expression level of MLCP, since MYPT1 and PPP1C $\delta$ are present at a 1:1 ratio in the MLCP holoenzyme. ${ }^{7}$ The expression levels of both CPI-17 and MYPT1 in GI smooth muscles differ in different regions of the gut that have been examined. Although both MYPT1 and CPI-17 are ubiquitously expressed in GI smooth muscles, the CPI-17 expression level appears to correlate with the extent of PKC-mediated $\mathrm{Ca}^{2+}$ sensitization of force. ${ }^{20,45}$ An extreme example is the gizzard and aorta from American farm chickens, which lack CPI-17. ${ }^{46}$ In these tissues, agonist stimulations induce only a slight increase in the $\mathrm{Ca}^{2+}$ sensitivity. ${ }^{46}$

We found different levels of MYPT1 and CPI-17 in gastric fundus, gastric antrum, and proximal colon of mouse. ${ }^{47}$ The gastric fundus has highest levels of Rho-associated, coiled-coil containing protein kinase 2 (ROCK2), MYPT1, and CPI-17 relative to MLCK and MLC. The proximal colon has high levels of MLC, MLCK, CPI-17, and MYPT1, but a low level of ROCK2. The antrum has the lowest levels of CPI-17 and MYPT1, and ROCK2, but high levels of MLC and MLCK. The functional roles of RhoA/ROCK have been examined in smooth muscles from rat internal anal sphincter (IAS), rectum, and the anococcygeus. ${ }^{48}$ These studies showed the highest levels of RhoA, GTP-RhoA, ROCK2, MLC, phosphorylated MYPT1 T696, and phosphorylated MLC in the tonic smooth muscles of the IAS compared to 
the mostly phasic rectum and phasic anococcygeus smooth muscles. CPI-17, phosphorylated CPI-17 T38, and phosphorylated MYPT1 T853 levels were not determined. Overall, these findings from different functional regions of the gut suggest that tonic GI smooth muscles may rely more on $\mathrm{Ca}^{2+}$ sensitization mechanisms for tone and contractions than phasic smooth muscles, which may rely more on MLCK activity.

\section{Inhibition of Myosin Light Chain Phosphatase Activity by CPI-17 Phosphorylation}

CPI-17 (17 kDa PKC-potentiated inhibitory protein of type 1 protein phosphatase, PPP1R14A) is the endogenous heat stable, smooth muscle-specific, inhibitory protein of MLCP. ${ }^{49,50}$ When CPI-17 is phosphorylated at T38, it binds to and inhibits MLCP (Figure). ${ }^{49,50}$ Three CPI-17 homologs are found in the human genome, and each one can potently inhibit MLCP activity. ${ }^{49,51,52} \mathrm{CPI}-$ 17 can be phosphorylated by multiple kinases. In smooth muscle, CPI-17 phosphorylation occurs in response to agonist stimulation through activation of $\mathrm{PKC}, \mathrm{ROCK}$, or integrin-linked kinase (ILK). ${ }^{24,53,54}$ PKC appears to be the major kinase that phosphorylates CPI-17 in GI smooth muscles. While PKC $\alpha$ and PKC $\delta$ are the primary kinases for $\mathrm{CPI}-17$ phosphorylation in response to agonist stimulation, CPI-17 can also bind to the regulatory domain of $\mathrm{PKC}$ isoforms, including $\alpha$, and the "non-traditional" $\mathrm{PKCs} \varepsilon, \lambda, \zeta$, and $\mu .{ }^{55}$ Zipper-interacting kinase (ZIPK) and p21-activated kinase can also directly phosphorylate isolated CPI-17 at T38. ${ }^{56,57}$ Phosphorylated CPI-17 selectively inhibits MLCP with an $\mathrm{IC}_{50}$ value of approximately $1 \mathrm{nM}$, due to the association of the PPP1C $\delta$ catalytic subunit with MYPT1 ${ }^{58,59}$ Computer modeling predicts direct binding between MYPT1 and phospho-CPI-17, suggesting that MYPT1 may dock CPI-17 to the MLCP holoenzyme, accounting for the specific inhibition of MLCP by CPI- $17 .{ }^{60}$ Furthermore, when bound to MYPT1, the PPP1Cd catalytic subunit of MLCP is unable to hydrolyze phospho-Thr38 of CPI-17, so phospho$\mathrm{CPI}-17$ is able to bind at the active site of $\mathrm{PPP} 1 \mathrm{C} \delta$ and suppress its activity. $^{59}$

\section{Inhibition of Myosin Light Chain Phosphatase Activity by MYPT1 Phosphorylation}

It is well established that MLCP activity is regulated by Ser/ Thr phosphorylation of MYPT1. Although several MYPT1 phosphorylation sites have been identified, 2 Thr residues (ie, T694 and T852; T697 and T855; T696 and T853, mouse, rat, and human isoform numbering, respectively) are the most important for eliciting $\mathrm{Ca}^{2+}$ sensitization. ${ }^{25}$ Several protein kinases, including ROCK, ZIPK, ILK, myotonic dystrophy kinase, Raf-1 and p21-activated protein kinases are known to phosphorylate the T696 residue. ${ }^{21,26}$ ROCK appears to be the major kinase phosphorylating MYPT1 at T853 in comparison to the other MYPT1 kinases. ${ }^{23,24,61}$ There are 2 isoforms of ROCK, ROCK1 and 2, which have similar tissue distributions and share $65 \%$ sequence homology at the amino acid level. ${ }^{62,63}$ In addition to regulating MLC phosphorylation via MYPT1 phosphorylation and inhibition of MLCP activity, both ROCK isoforms are important regulators of cell growth, migration, and morphology via control of actin cytoskeletal assembly. ${ }^{63}$ Despite their sequence similarity and overlapping substrate specificities, gene-silencing and selective knock-out models indicate distinct roles for each isoform. ${ }^{63}$ Although both ROCK1 and ROCK2 can phosphorylate MYPT1 at T853, only ROCK2 can directly bind to MYPT1, resulting in a greater degree of T853 phosphorylation. ${ }^{64}$ In addition, in vascular smooth muscles, the myosin phosphataserho interacting protein (MP-RIP, also M-RIP, p116 ${ }^{\mathrm{RIP}}$ ) co-localizes GTP-RhoA with ROCK2 bound to MYPT1 to selectively stimulate ROCK2 phosphorylation of MYPT1 T853. ${ }^{64,65} \mathrm{We}$ found that M-RIP is expressed in murine gastric antrum, gastric fundus, and proximal colon smooth muscles, suggesting that a similar mechanism is present in GI smooth muscle tissues. ${ }^{47}$ ROCK shows a 3-fold preference for T853 rather than T696, while the ZIPK shows a 6.7-fold preference for T696 over T853. ${ }^{66}$ Both of these inhibitory phosphorylation sites are immediately preceded by Ser residues that match the cyclic AMP- and cGMP-dependent protein kinase consensus phosphorylation motif. ${ }^{67}$ Phosphorylation of S695 interferes with subsequent inhibitory phosphorylation of T696 by ROCK, causing a decrease in MLCP inhibition, and potentially, an increase in MLC dephosphorylation. ${ }^{67}$ Whether S852 phosphorylation has a similar effect on T853 phosphorylation by ROCK has not yet been investigated. ${ }^{67}$ Other signaling pathways that impact the activities of these kinases thus have the potential to indirectly affect MLCP activity also. Much effort has been directed toward the determining the functional consequences and the physiological importance of MYPT1 phosphorylation at these two inhibitory threonine residues. ${ }^{21}$ Currently, phosphorylation of T696 is thought to directly inhibit MLCP activity towards MLC, via pseudosubstrate inhibition, whereas T853 phosphorylation is believed to cause dissociation of MLCP from myosin and/or inhibit MLCP activity directly. ${ }^{68}$ The latter hypothesis is supported by the recent study using a genetic approach to knock-in nonphosphorylatable Ala for T852 or T694. ${ }^{69}$ The MYPT1 T694A 
mutation was found to significantly inhibit sustained force as well as MLC phosphorylation, while the T852A mutation had no significant effect on maximal force development and little effect on force maintenance in neonatal bladder smooth muscle. These findings indicate that phosphorylated T694, but not T852, inhibits MLCP activity. However, ROCK inhibitors still inhibited force development and force maintenance in bladder smooth muscles with the T852A mutation to similar extents as wild-type muscles, without affecting MLC phosphorylation. ${ }^{69}$

Why did the T852 mutation have no significant effect on maximal force development and little effect on force maintenance in bladder smooth muscle, and yet ROCK inhibitors were still able to inhibit contractile responses? Much of the evidence supporting a role of MYPT1 T852 phosphorylation in contributing to enhanced MLC phosphorylation in intact tissues has been obtained using pharmacological inhibitors of ROCK. Although we observed a decrease in constitutive MLC S19 phosphorylation in mouse gastric fundus smooth muscles with the ROCK inhibitor Y-26732, both MYPT1 T852 and T694 phosphorylation were reduced by Y-26732. ${ }^{47}$ ROCK inhibition also reduced the carbachol $(\mathrm{CCh})$ evoked increase in MLC S19 phosphorylation, but also inhibited the increase in MYPT1 T852 and T694 phosphorylation. ${ }^{70}$ Furthermore, as noted earlier, both ROCK isoforms phosphorylate other proteins that can potentially affect smooth muscle contraction. In rat aorta and mesenteric arteries, ROCK appears to be involved in agonist activation of $\mathrm{Ca}^{2+}$ entry distinct from voltage or store operated channels. ${ }^{71}$ Treatment of rat resistance arteries with a ROCK inhibitor inhibited F-actin polymerization and contraction. ${ }^{72}$ ROCK can also affect actin dynamics through the phosphorylation of LIM-kinase, which phosphorylates and inactivates cofilin's ability to sever $\mathrm{F}$-actin. ${ }^{73-75}$ The resulting increase in actin polymerization is associated with enhanced force development by linking the actomyosin motor complex to the extracellular matrix through membrane adhesions. ${ }^{76}$ The ROCK inhibitors Y-27632 and H-1152 have also been shown to decrease the contractions of mouse colon smooth muscles evoked by nerve stimulation, $\mathrm{CCh}$ and substance $\mathrm{P}$ partly by inhibition of non-selective cation conductances. ${ }^{77}$ Finally, the commonly used ROCK inhibitors Y-26732, HA-1152, and fasudil, are nonselective with respect to ROCK1 and ROCK $2 .{ }^{63}$ Thus, the use of pharmacological ROCK inhibitors will affect the activities of both ROCK1 and ROCK2, and not only inhibit MYPT1 T852 phosphorylation, but also affect multiple proteins involved in smooth muscle contraction.

\section{Activation of $\mathrm{Ca}^{2+}$ Sensitization Mechanisms in Gastrointestinal Smooth Muscles}

Much of the evidence for $\mathrm{Ca}^{2+}$ sensitization in GI smooth muscles comes from studies examining the effects of ROCK or PKC inhibitors, or other kinase inhibitors, on agonist-evoked contractile responses. The experimental evidence from this approach suggests that stimulation of GI smooth muscles by agonists can potentially elicit $\mathrm{Ca}^{2+}$ sensitization, as indicated by inhibition of the agonist-evoked contractile responses. Other studies have additionally directly examined the effects of ROCK or PKC inhibitors, or other kinase inhibitors, on agonist-evoked contractile responses and on CPI-17, MYPT1, and MLC phosphorylation.

Nerve-evoked and CCh-evoked contraction of both esophageal and lower esophageal sphincter (LES) smooth muscles are inhibited by ROCK inhibitors, while PKC inhibitors inhibited the contractions of esophageal but not LES smooth muscles, ${ }^{78-80} \mathrm{It}$ has been concluded from these findings that $\mathrm{Ca}^{2+}$ sensitization by ROCK plays an important role in the maintenance of LES tone. ${ }^{17}$ It has been reported that the ROCK inhibitor Y-27632 inhibits gastric motility in vivo in rats. ${ }^{81}$ In gastric fundus smooth muscles, ROCK inhibitors, but not PKC inhibitors, suppress the contractile responses to $\mathrm{CCh}, \mathrm{KCl}$, and cholinergic neurotransmission evoked by electrical field stimulation, and also relaxed fundus smooth muscles pre-contracted by $\mathrm{CCh}$ or $\mathrm{KCl}^{82,83} \mathrm{In}$ isolated, permeabilized cells from guinea pig gastric fundus, PKC inhibitors did not inhibit CCh-induced cell shortening, although another study showed that PKC inhibitors do inhibit CCh-induced cell shortening. ${ }^{84,85}$ Similarly, ROCK inhibitors, but not PKC inhibitors, inhibited GTPand $\mathrm{CCh}$-induced $\mathrm{Ca}^{2+}$ sensitization in proximal colon longitudinal smooth muscles. ${ }^{86}$ In longitudinal smooth muscles from the distal colon, both ROCK and PKC inhibitors inhibited GTP- and CChinduced $\mathrm{Ca}^{2+}$ sensitization. ${ }^{86}$ However, in circular smooth muscles from the distal colon, PKC inhibitors but not ROCK inhibitors inhibited CCh-induced $\mathrm{Ca}^{2+}$ sensitization. ${ }^{86} \mathrm{In}$ rectal smooth muscles from the rat, ROCK inhibition significantly decreased spontaneous contractions and ROCK activity, but to lesser extents than in IAS smooth muscles. ${ }^{48}$ In mouse anococcygeus smooth muscle, $\mathrm{Ca}^{2+}$ sensitization induced by phenylephrine, norepinephrine, and $\mathrm{CCh}$ was markedly antagonized by ROCK inhibitors, and the contractile responses to $\mathrm{KCl}$-induced depolarization or excitatory electrical field stimulation were also highly sensitive to ROCK inhibitors. ${ }^{87,88}$

The phosphorylation of MYPT1, CPI-17, and MLC in various GI smooth muscles in response to contractile agonists has been 
investigated by a number of laboratories. These studies show that, in general, exogenously added contractile agonists elicit variable increases in MLC S19, CPI-17 T38, and MYPT1 T694 and T852 phosphorylation depending on the agonist used and the smooth muscle employed. In murine gastric fundus smooth muscles we found that CCh increases ROCK-dependent MYPT1 T852, but not T694, phosphorylation, and PKC-dependent CPI-17 T38 phosphorylation. ${ }^{70}$ Atropine-sensitive cholinergic neurotransmission evoked by electrical field stimulation only increased CPI-17 T38 phosphorylation. ${ }^{70}$ MLC S19 phosphorylation was only modestly increased by $\mathrm{CCh}$ stimulation. ${ }^{70}$ In murine gastric antrum smooth muscles we found that $\mathrm{CCh}$ or high extracellular $\mathrm{K}^{+}$increased the phosphorylation of CPI-17 T38 and MYPT1 T852, and modestly increased MYPT1 T694 phosphorylation. ${ }^{89}$ In gastric antrum smooth muscles from diabetic ob/ob mice, we found similar levels of CPI-17 expression and T38 phosphorylation in response to $\mathrm{CCh}$ or high $\mathrm{K}^{+}{ }^{89}$ However, ROCK2 expression and MYPT1 T852 phosphorylation were transiently decreased. ${ }^{89}$ MLC S19 basal phosphorylation levels, and the increase in S19 phosphorylation by $\mathrm{CCh}$ or high $\mathrm{K}^{+}$were also lower in ob/ob gastric antrum smooth muscles. ${ }^{89}$ In longitudinal smooth muscles from the rat ileum, $\mathrm{CCh}$ increases ROCK-dependent MYPT1 T853, but not T697, phosphorylation, and PKC-dependent CPI-17 T38 phosphorylation. ${ }^{90,91}$ PKC inhibition inhibited T38 phosphorylation, while ROCK inhibitors inhibited both T855 and T38 phosphorylation. ${ }^{90-92}$ CPI-17 expression and phosphorylation, and MLC phosphoryl-ation are decreased in animal models of colitis, and in human patients with ulcerative colitis. ${ }^{93,94}$ ROCK and MYPT1 phosphorylation contribute substantially to the constitutive tonic contracted state of the IAS. $^{95}$ ROCK inhibition decreases the basal tone, and reduces the phosphorylation levels of MYPT1 T697, CPI-17 T38, and MLC S19 in rat IAS smooth muscles. ${ }^{48,95}$ With human IAS smooth muscles, it has been reported that PKC inhibitors significantly decrease T38 phosphorylation, with modest effects on IAS smooth muscle tone, while ROCK inhibition produces significantly greater relaxation of IAS smooth muscle cells than PKC inhibition. ${ }^{95,96}$ However, it has also been reported that the PKC activator PDBu relaxes opossum IAS. ${ }^{97}$

A variety of non-cholinergic agonists have been reported to increase CPI-17 and MYPT1 phosphorylation and activate myofilament $\mathrm{Ca}^{2+}$ sensitization. In cultured cells isolated from rabbit distal stomach smooth muscles, motilin increased the phosphorylation of CPI-17 by PKC and MYPT1 by ROCK, leading to inhibition of MLCP and sustained MLC phosphorylation and contraction. ${ }^{98}$ In contrast, lysophosphatidic acid increased CPI-17 phosphorylation by PKC, but although ROCK was activated, MYPT1 phosphorylation at T696 was masked by MYPT1 phosphorylation at S695. ${ }^{99}$ The PAR2 activating peptide SLIGRL (PAR2-AP) increased MYPT1 phosphorylation but not CPI-17 phosphorylation in cultured cells isolated from rabbit distal stomach smooth muscles. ${ }^{99}$ Androgens have recently been shown to potentiate ileal and colonic smooth muscle contractions by a non-genomic mechanism involving stimulation of polyamine synthesis which induces calcium sensitization of contractile machinery by ROCK and PKC activation along with increased CPI-17 phosphorylation. ${ }^{100}$ Angiotensin IIinduced contractions of rat LES and IAS smooth muscle cells are inhibited by Clostridium botulinum C3 exozyme, HA-1077, and Y-27632, suggesting a role for ROCK. ${ }^{101}$ It has been reported that thromboxane $\mathrm{A} 2$ and prostaglandin $\mathrm{F} 2 \alpha$, the end products of the renin-angiotensin system and arachidonic acid pathways, increase IAS tone via activation of RhoA/ROCK and increased MYPT1 T696 and MLC S19 phosphorylation. ${ }^{101-103}$

Other possible mechanisms for $\mathrm{Ca}^{2+}$-sensitization in GI smooth muscles have also been reported. $\mathrm{Ca}^{2+}$-independent MLCKs have been identified through the use of phosphatase inhibition at low $\left[\mathrm{Ca}^{2+}\right] \cdot{ }^{61,104}$ Application of microcystin induces MLC di-phosphorylation at S19 and T18, and contraction of $\beta$-escinpermeabilized rat ileal smooth muscles. ${ }^{104,105}$ The PKC, MEK, and p38MAPK inhibitors GF-109203x, PD-98059, and SB-203580, respectively, each significantly reduced this contraction. ${ }^{104,105} \mathrm{GF}-$ 109203x and PD-98059 decreased MYPT1 T697 phosphorylation, while SB-203580 reduced CPI-17 T38 phosphorylation. ${ }^{105} \mathrm{~A}$ ZIPK inhibitor (SM1 peptide) and the ROCK inhibitor Y-27632 had little effect on microcystin-induced contractions at $\mathrm{pCa} 9{ }^{105}$ This study showed that PKC, ERK1/2, and p38MAPK pathways facilitate the microcystin-induced contraction at low $\mathrm{Ca}^{2+}$ concentrations by contributing to the inhibition of MLCP activity through phosphorylation of MYPT1 or CPI-17. Previous reports suggested several candidates for MLC di-phosphorylation by $\mathrm{Ca}^{2+}$ independent MLCKs including ROCK, PKC, MAPK-activated protein kinase-2 (MAPKAPK2), MAPK-activated protein kinase$1 \mathrm{~b}$ (RSK-2), ILK, and ZIPK. ${ }^{53,106-111}$ Among these kinases, only ROCK and ILK have been shown to induce MLC phosphorylation and contraction of ileum smooth muscles. ${ }^{53,106}$ Taken together, ILK has emerged as the likely candidate to fill the role of $\mathrm{Ca}^{2+}$ independent MLCK for the di-phosphorylation of MLC in GI smooth muscle. ${ }^{112}$

In addition, it was recently reported that ERK and p38MAPK contribute to $\mathrm{Ca}^{2+}$ sensitization of ileal longitudinal smooth muscle contraction and regulate MLCP activity independently of MYPT1 
and CPI-17 phosphorylation. ${ }^{113}$ ERK or p38MAPK inhibitors inhibited CCh-induced contractile force and decreased MLCP activity, as measured by phosphatase activity in lysates. However, MYPT1 T697 and T855, and CPI-17 T38 phosphorylation were not affected by MEK or p38MAPK inhibition. Thus, ERK and p38MAPK may contribute to CCh-induced sustained contraction in an MLC phosphorylation dependent manner, and inhibit MLCP activity by a novel mechanism. ${ }^{113}$

\section{CPI-17 and MYPT1 Are Constitutively Phosphorylated in Gastrointestinal Smooth Muscles}

Some of the evidence for the constitutive phosphorylation of CPI-17 and MYPT1 in GI smooth muscles comes from studies investigating the effects of $\mathrm{PKC}$ and ROCK inhibitors on spontaneous tone. In the LES, ROCK inhibitors have been shown to produce full relaxation of the basal tone in human and various animal species, while PKC inhibitors have only limited effects on LES basal tone. ${ }^{17,80}$ These studies suggest that a mechanism of $\mathrm{Ca}^{2+}$ sensitization mediated by the RhoA/ROCK pathway plays an important role in the basal tone in the LES, although MYPT1 and CPI-17 phosphorylation in the LES has not been measured. Interestingly, the proton pump inhibitor pantoprazole inhibited MYPT1 T853 phosphorylation evoked by CCh in gastric and LES tissue, suggesting that it may also be a ROCK inhibitor, although it had no effect on constitutive MYPT1 or CPI-17 phosphorylation. ${ }^{114}$ It has been reported that PDBu-evoked contraction of cells isolated from human IAS smooth muscles are reduced by a ROCK inhibitor, but not by a PKC inhibitor, although PKC was activated, although another study reported that PDBu relaxes opossum IAS smooth muscles and cells isolated from opossum IAS smooth muscles. ${ }^{97,115}$ Several of the studies previously mentioned examining CPI-17 and MYPT1 phosphorylation in response to contractile agonists show variable, but significant levels of constitutive CPI-17 and MYPT1 phosphorylation in the un-stimulated control tissues. In GI smooth muscles that have been examined, constitutive CPI-17 phosphorylation is low, while MYPT1 phosphorylation at T694 and T852 is quite significant. ${ }^{47,70,89,98,105,116-119}$ Typically, PKC inhibitors decrease the constitutive phosphorylation of CPI-17 at T38, and ROCK inhibitors decrease the constitutive phosphorylation of MYPT1 at T853. ${ }^{22,120}$ However, the sensitivity of constitutive CPI-17 T38 and MYPT1 T696 phosphorylation to PKC and ROCK inhibitors varies among different GI smooth muscles. ROCK inhibitors have no effect on basal T38 phosphorylation in the gastric fundus, antrum, and proximal colon, but partially decrease basal T38 phosphorylation in the ileum, IAS, and rectum. ${ }^{47,48}$ Basal T696 phosphorylation is partially decreased by nifedipine, PKC inhibitors, or ROCK inhibitors in IAS, ileum, or gastric fundus, while in rectum, only ROCK inhibitors partially decrease basal T696 basal phosphorylation. ${ }^{47,48}$ In gastric antrum and proximal colon, PKC or ROCK inhibitors have no effect on basal T696 phosphorylation. ${ }^{47}$

These findings suggest that tissue specific mechanisms likely regulate T696 phosphorylation in GI smooth muscles, with ROCK and PKC involved in maintaining pT696 in gastric fundus, ileum, rectum, and IAS smooth muscles, but not in antrum and proximal colon smooth muscles. Additional kinases can phosphorylate T696 in vivo, including MYPT1 kinase, integrin-linked kinase, myotonic dystrophy protein kinase, p21-activated protein kinase, and Raf- $1{ }^{57,121-125}$ Which kinases maintain constitutive MYPT1 T696 phosphorylation in the gastric antrum and proximal colon smooth muscles have not been identified. The study of embryonic bladder smooth muscle by Chen et al. showed that the constitutive MYPT1 T694 phosphorylation was not further increased by phosphatase inhibition. ${ }^{69}$ In addition, the MYPT1 T694A mutation resulted in significantly decreased force generation and reduced MLC20 phosphorylation. ${ }^{69}$ These findings indicate that MYPT1 T694 may be $100 \%$ phosphorylated, and is responsible for suppressing MLCP activity under resting conditions. ${ }^{69}$ Interestingly, these findings may explain why MYPT1 T694 phosphorylation is sometimes not further increased by contractile agonists. ${ }^{70}$

Finally, basal CPI-17 and MYPT1 phosphorylation has typically been measured in GI smooth muscles in which motor nerve activity is blocked with tetrodotoxin. However, ongoing kinase activity must be present to maintain this basal CPI-17 and MYPT1 phosphorylation. What are the mechanisms underlying the constitutive kinase activities that sustain CPI-17 and MYPT1 phosphorylation in the absence of motor neuron stimulation? Because of the importance of the basal phosphorylation levels of CPI17 and MYPT1 for basal tone and in setting the sensitivity of the contractile machinery to neuronal stimulation, unraveling the mechanisms responsible for the basal kinase activities in the absence of neural signals is important for a more complete understanding of GI smooth muscle contraction.

\section{Exogenous vs Endogenous Cholinergic Stimulation}

Only a few studies have examined the stimulation of $\mathrm{Ca}^{2+}$ sensitization in GI smooth muscles by endogenous neurotransmission. 
Typically, studies have used exogenously added neurotransmitter substances as agonists to activate $\mathrm{Ca}^{2+}$ sensitization mechanisms in smooth muscle cells. The rationale underlying this approach is that the binding of an exogenously added contractile agonist to its receptor on smooth muscle cells mimics the binding of the endogenous neurotransmitter to its post-junctional receptor on a smooth muscle cell. However, several lines of evidence indicate that motor neurotransmission in the GI tract is more complicated than simple release of transmitter from nerve terminals and binding to receptors on smooth muscle cells. The "neuro-effector" junction in the tunica muscularis consists of synaptic-like connectivity with specialized cell types; interstitial cells of Cajal (ICC) and platelet-derived growth factor receptor alpha $\left(\mathrm{PDGFR}^{+}\right)$cells. ${ }^{126}$ Smooth muscle cells are electrically coupled to ICC and PDGFR $\alpha^{+}$cells, forming an integrated neuroeffector unit called the SIP syncytium. ${ }^{127,128}$ The receptors and ion channels expressed by each SIP cell type are overlapping, and conductance changes in any type of SIP cell affects the excitability and responses of the entire syncytium. ${ }^{126}$ Interstitial cells of Cajal (ICC-IM) serve as mediators of motor neurotransmission as shown by their immediate proximity to enteric nerve varicosities, presence of synaptic structures between nerve varicosities and ICC-IM, and expression of neurotransmitter receptors. ${ }^{126,129}$ For the major excitatory neurotransmitter in the GI tract, acetylcholine (ACh), we recently showed that cholinergic neurotransmission and the exogenously added cholinergic agonist $\mathrm{CCh}$ have different effects on $\mathrm{Ca}^{2+}$ sensitization mechanisms. ${ }^{70}$ Comparing tetrodotoxin and atropine-sensitive frequency dependent contractions of murine gastric fundus with atropine-sensitive CCh-evoked contractions, we found that cholinergic neurotransmission activated CPI-17 T38 phosphorylation by PKC, while CCh activated CPI-17 T38 phosphorylation by PKC, and additionally recruited MYPT1 T853 phosphorylation by ROCK. ${ }^{70}$ Only when the access of neurally released ACh to smooth muscle cells was artificially enabled by inhibiting cholinesterase activity, or by the absence of ICC in $W / W^{V}$ mice, was MYPT1 T853 phosphorylation increased by cholinergic neurotransmission. ${ }^{70}$ Similarly, in urinary bladder smooth muscles, neurostimulation results in increased phosphorylation of CPI-17, but not MYPT1, while pharmacological stimulation of muscarinic receptors increases both CPI-17 and MYPT1 phosphorylation. ${ }^{130}$ These data suggest that, unlike exogenously applied cholinergic agonists, ACh released from neurons is restricted, physically and enzymatically, to adjacent areas created by the close apposition of nerve varicosities and ICC. Due to this compartmentalization, ACh released from neurons does not appear to reach the receptors on smooth muscle cells that are linked to activation of ROCK and
MYPT1 phosphorylation in GI smooth muscle cells. The increase in T853 phosphorylation observed in both of these smooth muscle tissues by exogenous agonists may be due to artificially intense activation of signaling mechanisms by pharmacological mechanisms that are not observed physiologically.

\section{Summary}

It has become apparent that $\mathrm{Ca}^{2+}$ sensitization mechanisms are important regulatory pathways in GI smooth muscles. Our understanding of the biochemical basis for the regulation of MLCP activity and MLC phosphorylation in smooth muscles has steadily advanced during the last 20 years. Studies have revealed that PKC, CPI-17, ROCK, and MYPT1 are the key effectors regulating MLCP activity in diverse GI smooth muscle tissues. PKC primarily phosphorylates CPI-17, while ROCK primarily phosphorylates MYPT1 (T853> T696). Several other kinases can phosphorylate T696, including PKC, ZIPK, ILK, myotonic dystrophy kinase, Raf-21, and p21-activated kinase. Thus, a cooperative network of protein kinase activities likely contributes to the MLCP inhibition observed during $\mathrm{Ca}^{2+}$ sensitization. There is also a dynamic regulation of kinase activities responsible for the basal levels of constitutive CPI-17 and MYPT1 phosphorylation, resulting in constitutive inhibition of MLCP and a basal level of MLC phosphorylation. Because the constitutive phosphorylation of CPI-17 and MYPT1 is important for maintaining basal tone and in setting the sensitivity of the contractile machinery to contractile stimuli, determining the mechanisms maintaining these basal kinase activities is important for a more complete understanding of GI smooth muscle contraction. Genetic knock-in of non-phosphorylatable MYPT1 T694A and T852A mutants suggest that phosphorylated T694 is responsible for direct MLCP inhibition, while phosphorylated T852 may mediate the effects of ROCK on enhancing force development through dynamic reorganization of the actin cytoskeleton at membrane adhesions connected to the extracellular matrix. Due to the localized nature of neurotransmitter release from motor neuron varicosities, and the contribution of the specialized ICC to neurotransmission in GI smooth muscles, $\mathrm{Ca}^{2+}$ sensitization mechanisms activated by exogenously added contractile agonists may not mimic the $\mathrm{Ca}^{2+}$ sensitization mechanisms activated by endogenous neurotransmitter release. Our findings suggest that the degree of activation of $\mathrm{Ca}^{2+}$ sensitization pathways depends upon the strength of the signal. In most regions of the GI tract, ICC effectively shield other cells from neurotransmitters, confining neurally released substances to receptors on cells that are immediately adjacent to where 
they are released. Thus, unlike bath-applied substances, neurally released transmitters might not be available to bind to receptors of other postjunctional cells to recruit additional $\mathrm{Ca}^{2+}$ sensitization pathways. Due to the functional diversity of GI smooth muscle tissues, the relative importance of PKC and ROCK activation to myofilament $\mathrm{Ca}^{2+}$ sensitization likely differs depending on the nature of the stimulus and the particular GI smooth muscle tissue. Each particular GI smooth muscle will likely have different rules regarding how MLCP activity and $\mathrm{Ca}^{2+}$ sensitivity are regulated during healthy physiological functioning. However, the regulation of $\mathrm{Ca}^{2+}$ sensitization mechanisms may be altered in pathophysiological conditions affecting GI motility. It will be important to elucidate how the mechanisms and signaling pathways underlying $\mathrm{Ca}^{2+}$ sensitization are altered during GI dysmotilities. This will help us to not only better understand GI smooth muscle pathophysiology, but also help develop new pharmacological strategies for the treatment of GI motility disorders.

Financial support: The author was supported by National Institutes of Health Grant P30-GM110767, and by a Pilot and Feasibility Grant from the NIDDK Diabetic Complications Consortium (DiaComp, www.diacomp.org), grant DK076169.

\section{Conflicts of interest: None.}

\section{References}

1. Sanders KM. Invited review: mechanisms of calcium handling in smooth muscles. J Appl Physiol 2001;91:1438-1449.

2. Chacko S, Conti MA, Adelstein RS. Effect of phosphorylation of smooth muscle myosin on actin activation and $\mathrm{Ca}^{2+}$ regulation. Proc Natl Acad Sci USA 1977;74:129-133.

3. Kamm KE, Stull JT. The function of myosin and myosin light chain kinase phosphorylation in smooth muscle. Annu Rev Pharmacol Toxicol 1985;25:593-620.

4. Somlyo AP, Himpens B. Cell calcium and its regulation in smooth muscle. FASEB J 1989;3:2266-2276.

5. Somlyo AP, Somlyo AV. $\mathrm{Ca}^{2+}$ sensitivity of smooth muscle and nonmuscle myosin II: Modulated by $G$ proteins, kinases, and myosin phosphatase. Physiol Rev 2003;83:1325-1358.

6. Hartshorne DJ, Ito M, Erdödi F. Role of protein phosphatase type 1 in contractile functions: myosin phosphatase. J Biol Chem 2004;279: 37211-37214.

7. Shirazi A, lizuka K, Fadden P, et al. Purification and characterization of the mammalian myosin light chain phosphatase holoenzyme. The differential effects of the holoenzyme and its subunits on smooth muscle. J
Biol Chem 1994;269:31598-31606.

8. Ozaki H, Gerthoffer WT, Publicover NG, Fusetani N, Sanders KM. Time-dependent changes in $\mathrm{Ca}^{2+}$ sensitivity during phasic contraction of canine antral smooth muscle. J Physiol 1991;440:207-224.

9. Yagi S, Becker PL, Fay FS. Relationship between force and $\mathrm{Ca}^{2+}$ concentration in smooth muscle as revealed by measurements on single cells. Proc Natl Acad Sci USA 1988;85:4109-4113.

10. Gerthoffer WT, Murphey KA, Mangini J, Boman S, Lattanzio FA Jr. Myosin phosphorylation and calcium in tonic and phasic contractions of colonic smooth muscle. Am J Physiol 1991;260(Pt 1):G958-G964.

11. Himpens B, Casteels R. Different effects of depolarization and muscarinic stimulation on the $\mathrm{Ca}^{2+}$-force relationship during the contractionrelaxation cycle in the guinea-pig ileum. Pflügers Archive 1990;416:2835 .

12. Morgan JP, Morgan KG. Stimulus-specific patterns of intracellular calcium levels in smooth muscle of ferret portal vein. J Physiol 1984;351: 312-317.

13. Ozaki H, Stevens RJ, Blondfield DP, Publicover NG, Sanders KM. Simultaneous measurement of membrane potential, cytosolic $\mathrm{Ca}^{2+}$, and tension in intact smooth muscles. Am J Physiol 1991;260(Pt 1):C917C925.

14. Karaki H, Ozaki H, Hori M, et al. Calcium movements, distribution, and functions in smooth muscle. Pharmacol Rev 1997;49:157-230.

15. Bitar KN. Function of gastrointestinal smooth muscle: from signaling to contractile proteins. Am J Med 2003;115(suppl 3A):15S-23S.

16. Gerthoffer WT. Signal-transduction pathways that regulate visceral smooth muscle function. III. Coupling of muscarinic receptors to signaling kinases and effector proteins in gastrointestinal smooth muscles. Am J Physiol Gastrointest Liver Physiol 2005;288:G849-G853.

17. Harnett KM, Cao W, Biancani P. Signal-transduction pathways that regulate smooth muscle function I. Signal transduction in phasic (esophageal) and tonic (gastroesophageal sphincter) smooth muscles. Am J Physiol Gastrointest Liver Physiol 2005;2005:G407-G416.

18. Kitazawa T, Gaylinn BD, Denney GH, Somlyo AP. G-protein-mediated $\mathrm{Ca}^{2+}$ sensitization of smooth muscle contraction through myosin light chain phosphorylation. J Biol Chem 1991;266:1708-1715.

19. Kitazawa T, Somlyo AP. Desensitization and muscarinic re-sensitization of force and myosin light chain phosphorylation to cytoplasmic $\mathrm{Ca}^{2+}$ in smooth muscle. Biochem Biophys Res Comm 1990;172:1291-1297.

20. Hirano K. Current topics in the regulatory mechanism underlying the $\mathrm{Ca}^{2+}$ sensitization of the contractile apparatus in vascular smooth muscle. J Pharmacol Sci 2007;104:109-115.

21. Ito M, Nakano T, Erdodi F, Hartshorne D. Myosin phosphatase: Structure, regulation and function. Mol Cell Biochem 2004;259:197209.

22. Murthy KS. Signaling for contraction and relaxation in smooth muscle of the gut. Annu Rev Physiol 2006;68:345-374.

23. Feng J, Ito M, Ichikawa K, et al. Inhibitory phosphorylation site for Rho-associated kinase on smooth muscle myosin phosphatase. J Biol Chem 1999;274:37385-37390.

24. Kitazawa T, Eto M, Woodsome TP, Khalequzzaman M. Phosphorylation of the myosin phosphatase targeting subunit and CPI-17 during 
$\mathrm{Ca}^{2+}$ sensitization in rabbit smooth muscle. J Physiol 2003;546(Pt 3): 879-889.

25. Grassie ME, Moffat LD, Walsh MP, MacDonald JA. The myosin phosphatase targeting protein (MYPT) family: a regulated mechanism for achieving substrate specificity of the catalytic subunit of protein phosphatase type 1d. Arch Biochem Biophys 2011;510:147-159.

26. Matsumura F, Hartshorne DJ. Myosin phosphatase target subunit: Many roles in cell function. Biochem Biophys Res Comm 2008;369: 149-156.

27. Eto M. Regulation of cellular protein phosphatase-1 (PP1) by phosphorylation of the CPI-17 family, C-kinase-activated PP1 Inhibitors. J Biol Chem 2009;284:35273-35277.

28. Alessi D, MacDougall LK, Sola MM, Ikebe M, Cohen P. The control of protein phosphatase-1 by targetting subunits. The major myosin phosphatase in avian smooth muscle is a novel form of protein phosphatase-1. Eur J Biochem 1992;210:1023-1035.

29. Pato MD, Tulloch AG, Walsh MP, Kerc E. Smooth muscle phosphatases: structure, regulation, and function. Can J Physiol Pharmacol 1994;72:1427-1433.

30. Bollen M, Peti W, Ragusa MJ, Beullens M. The extended PP1 toolkit: designed to create specificity. Trends Biochem Sci 2010;35:450-458.

31. Bollen M, Stalmans W. The structure, role, and regulation of type 1 protein phosphatases. Crit Rev Biochem Mol Biol 1992;27:227-281.

32. Cohen PT. Protein phosphatase 1--targeted in many directions. J Cell Sci 2002;115(Pt 2):241-256.

33. Ceulemans H, Bollen M. Functional diversity of protein phosphatase-1, a cellular economizer and reset button. Physiol Rev 2004;84:1-39.

34. Johnson D, Cohen P, Chen MX, Chen YH, Cohen PTW. Identification of the regions on the M110 subunit of protein phosphatase $1 \mathrm{M}$ that interact with the M21 subunit and with myosin. Eur J Biochem 1997;244:931-939.

35. Shimizu H, Ito M, Miyahara M, et al. Characterization of the myosinbinding subunit of smooth muscle myosin phosphatase. J Biol Chem 1994;269:30407-30411.

36. Khatri JJ, Joyce KM, Brozovich FV, Fisher SA. Role of myosin phosphatase isoforms in cGMP-mediated smooth muscle relaxation. J Biol Chem 2001;276:37250-37257.

37. Dippold RP, Fisher SA. Myosin phosphatase isoforms as determinants of smooth muscle contractile function and calcium sensitivity of force production. Microcirculation 2014;21:239-248.

38. Payne MC, Zhang HY, Prosdocimo T, et al. Myosin phosphatase isoform switching in vascular smooth muscle development. J Mol Cell Cardiol 2006;40:274-282.

39. Huang QQ, Fisher SA, Brozovich FV. Unzipping the role of myosin light chain phosphatase in smooth muscle cell relaxation. J Biol Chem 2004;279:597-603.

40. Surks HK, Mochizuki N, Kasai Y, et al. Regulation of myosin phosphatase by a specific interaction with cGMP- dependent protein kinase Ia. Science 1999;286:1583-1587.

41. Yuen SL, Ogut O, Brozovich FV. Differential phosphorylation of LZ+/ LZ- MYPT1 isoforms regulates MLC phosphatase activity. Arch Biochem Biophys 2014;562:37-42.
42. Chen YH, Chen MX, Alessi DR, et al. Molecular cloning of cDNA encoding the $110 \mathrm{kDa}$ and $21 \mathrm{kDa}$ regulatory subunits of smooth muscle protein phosphatase 1M. FEBS Lett 1994;356:51-55.

43. Arimura T, Suematsu N, Zhou YB, et al. Identification, characterization, and functional analysis of heart-specific myosin light chain phosphatase small subunit. J Biol Chem 2001;276:6073-6082.

44. Shichi D, Arimura T, Ishikawa T, Kimura A. Heart-specific small subunit of myosin light chain phosphatase activates Rho-associated kinase and regulates phosphorylation of myosin phosphatase target subunit 1 . J Biol Chem 2010;285:33680-33690.

45. Woodsome TP, Eto M, Everett A, Brautigan DL, Kitazawa T. Expression of CPI-17 and myosin phosphatase correlates with $\mathrm{Ca}^{2+}$ sensitivity of protein kinase $\mathrm{C}$-induced contraction in rabbit smooth muscle. $\mathrm{J}$ Physiol 2001;535(Pt 2):553-564.

46. Kitazawa T, Polzin AN, Eto M. CPI-17-deficient smooth muscle of chicken. J Physiol 2004;557(Pt 2):515-528.

47. Bhetwal BP, An CL, Fisher SA, Perrino BA. Regulation of basal LC20 phosphorylation by MYPT1 and CPI-17 in murine gastric antrum, gastric fundus, and proximal colon smooth muscles. Neurogastroenterol Motil 2011;23:e425-e436.

48. Patel CA, Rattan S. Spontaneously tonic smooth muscle has characteristically higher levels of RhoA/ROK compared with the phasic smooth muscle. Am J Physiol Gastrointest Liver Physiol 2006;291:G830G837.

49. Eto M, Karginov A, Brautigan DL. A novel phosphoprotein inhibitor of protein type-1 phosphatase holoenzymes. Biochemistry 1999;38: 16952-16957.

50. Eto M, Ohmori T, Suzuki M, Furuya K, Morita F. A novel protein phosphatase-1 inhibitory protein potentiated by protein kinase C. Isolation from porcine aorta media and characterization. J Biochem 1995; 118:1104-1107.

51. Liu QR, Zhang PW, Zhen Q, Walther D, Wang XB, Uhl GR. KEPI, a PKC-dependent protein phosphatase 1 inhibitor regulated by morphine. J Biol Chem 2002;277:13312-13320.

52. Liu QR, Zhang PW, Lin Z, et al. GBPI, a novel gastrointestinal- and brain-specific PP1-inhibitory protein, is activated by $\mathrm{PKC}$ and inactivated by PKA. Biochem J 2004;377(Pt 1):171-181.

53. Deng J, Sutherland C, Brautigan DL, Eto M, Walsh MP. Phosphorylation of the myosin phosphatase inhibitors, CPI-17 and PHI-1, by integrin-linked kinase. Biochem J 2002;367(Pt 2):517-524.

54. Koyama M, Ito M, Feng J, et al. Phosphorylation of CPI-17, an inhibitory phosphoprotein of smooth muscle myosin phosphatase, by Rhokinase. FEBS Lett 2000;475:197-200.

55. Zemlickova E, Johannes FJ, Aitken A, Dubois T. Association of CPI17 with protein kinase $\mathrm{C}$ and casein kinase I. Biochem Biophys Res Comm 2004;316:39-47.

56. MacDonald JA, Eto M, Borman MA, Brautigan DL, Haystead TAJ. Dual Ser and Thr phosphorylation of CPI-17, an inhibitor of myosin phosphatase, by MYPT-associated kinase. FEBS Lett 2001;493:91-94.

57. Takizawa N, Koga Y, Ikebe M. Phosphorylation of CPI-17 and myosin binding subunit of type 1 protein phosphatase by p21-activated kinase. Biochem Biophys Res Comm 2002;297:773-778. 
58. Eto M, Kitazawa T, Brautigan DL. Phosphoprotein inhibitor CPI-17 specificity depends on allosteric regulation of protein phosphatase-1 by regulatory subunits. Proc Natl Acad Sci USA 2004;101:8888-8893.

59. Senba S, Eto M, Yazawa M. Identification of trimeric myosin phosphatase $(\mathrm{PP} 1 \mathrm{M})$ as a target for a novel PKC-potentiated protein phosphatase-1 inhibitory protein (CPI17) in porcine aorta smooth muscle. J Biochem 1999;125:354-362.

60. Eto M, Kitazawa T, Matsuzawa F, et al. Phosphorylation-induced conformational switching of CPI-17 produces a potent myosin phosphatase inhibitor. Structure 2007;15:1591-1602.

61. Wilson D, Susnjar M, Kiss E, Sutherland C, Walsh M. Thromboxane A2-induced contraction of rat caudal arterial smooth muscle involves activation of $\mathrm{Ca}^{2+}$ entry and $\mathrm{Ca}^{2+}$ sensitization: Rho-associated kinasemediated phosphorylation of MYPT1 at Thr-855, but not Thr-697. Biochem J 2005;389(Pt 3):763-774.

62. Nakagawa O, Fujisawa K, Ishizaki T, Saito Y, Nakao K, Narumiya S. ROCK-I and ROCK-II, two isoforms of Rho-associated coiledcoil forming protein serine/threonine kinase in mice. FEBS Lett 1996;392:189-193.

63. Noma K, Oyama N, Liao JK. Physiological role of ROCKs in the cardiovascular system. Am J Physiol Cell Physiol 2006;290:C661-C668.

64. Wang Y, Zheng XR, Riddick N, et al. ROCK isoform regulation of myosin phosphatase and contractility in vascular smooth muscle cells. Circ Res 2009;104:531-540.

65. Riddick N, Ohtani Ki, Surks HK. Targeting by myosin phosphataseRhoA interacting protein mediates RhoA/ROCK regulation of myosin phosphatase. J Cell Biochem 2008;103:1158-1170.

66. Haystead TAJ. ZIP kinase, a key regulator of myosin protein phosphatase 1. Cell Sig 2005;17:1313-1322.

67. Wooldridge AA, MacDonald JA, Erdodi F, et al. Smooth muscle phosphatase is regulated in vivo by exclusion of phosphorylation of Threonine 696 of MYPT1 by phosphorylation of Serine 695 in response to cyclic nucleotides. J Biol Chem 2004;279:34496-34504.

68. Khasnis M, Nakatomi A, Gumpper K, Eto M. Reconstituted human myosin light chain phosphatase reveals distinct roles of two inhibitory phosphorylation sites of the regulatory subunit, MYPT1. Biochemistry 2014;53:2701-2709.

69. Chen CP, Chen X, Qiao YN, et al. In vivo roles for myosin phosphatase targeting subunit-1 phosphorylation sites T694 and T852 in bladder smooth muscle contraction. J Physiol 2015;593:681-700.

70. Bhetwal BP, Sanders KM, An C, Trappanese DM, Moreland RS, Perrino $\mathrm{BA} . \mathrm{Ca}^{2+}$ sensitization pathways accessed by cholinergic neurotransmission in the murine gastric fundus. J Physiol 2013;591:2971-2986.

71. Ghisdal P, Vandenberg G, Morel N. Rho-dependent kinase is involved in agonist-activated calcium entry in rat arteries. J Physiol 2003;551(Pt 3): 855-867.

72. Moreno-Dominguez A, Colinas O, El-Yazbi A, et al. $\mathrm{Ca}^{2+}$ sensitization due to myosin light chain phosphatase inhibition and cytoskeletal reorganization in the myogenic response of skeletal muscle resistance arteries. J Physiol 2013;591:1235-1250.

73. Bernard O. Lim kinases, regulators of actin dynamics. Int J Biochem Cell Biol 2007;39:1071-1076.
74. Maekawa M, Ishizaki T, Boku S, et al. Signaling from Rho to the actin Cytoskeleton through protein kinases ROCK and LIM-kinase. Science 1999;285:895-898.

75. Walsh MP, Cole WC. The role of actin filament dynamics in the myogenic response of cerebral resistance arteries. J Cereb Blood Flow Metab 2013;33:1-12.

76. Gunst SJ, Zhang W. Actin cytoskeletal dynamics in smooth muscle: a new paradigm for the regulation of smooth muscle contraction. Am J Physiol Cell Physiol 2008;295:C576-C587.

77. Bayguinov O, Dwyer L, Kim H, Marklew A, Sanders K, Koh S. Contribution of Rho-kinase to membrane excitability of murine colonic smooth muscle. Br J Pharmacol 2011;163:638-648.

78. Kim N, Cao W, Song IS, et al. Distinct kinases are involved in contraction of cat esophageal and lower esophageal sphincter smooth muscles. Am J Physiol Cell Physiol 2004;287:C384-C394.

79. Park SY, Song HJ, Sohn UD. Participation of Rho-associated kinase in electrical stimulated and acetylcholine-induced contraction of feline esophageal smooth muscle. Eur J Pharmacol 2009;607:220-225.

80. Sims SM, Chrones T, Preiksaitis HG. Calcium sensitization in human esophageal muscle: role for RhoA kinase in maintenance of lower esophageal sphincter tone. J Pharmacol Exp Ther 2008;327:178-186.

81. Tomomasa T, Takahashi A, Kaneko H, et al. Y-27632 inhibits gastric motility in conscious rats. Life Sci 1999;66:PL29-PL34.

82. Buyukafsar K, Levent A. Involvement of Rho/Rho-kinase signalling in the contractile activity and acetylcholine release in the mouse gastric fundus. Biochem Biophys Res Commun 2003;303:777-781.

83. Ratz PH, Meehl JT, Eddinger TJ. RhoA kinase and protein kinase C participate in regulation of rabbit stomach fundus smooth muscle contraction. Br J Pharmacol 2002;137:983-992.

84. Oishi K, Mita M, Ono T, Hashimoto T, Uchida MK. Protein kinase $\mathrm{C}$-independent sensitization of contractile proteins to $\mathrm{Ca}^{2+}$ in alphatoxin-permeabilized smooth muscle cells from the guinea-pig stomach. Br J Pharmacol 1992;107:908-909.

85. Oishi K, Ishibashi T, Nakamura S, Mita M, Uchida MK. Protein kinase $\mathrm{C}$ promotes spontaneous relaxation of streptolysin-o-permeabilized smooth muscle cells from the guinea-pig stomach. Life Sci 1999;64:1975-1987.

86. Takeuchi T, Kushida M, Hirayama N, Kitayama M, Fujita A, Hata F. Mechanisms involved in carbachol-induced $\mathrm{Ca}^{2+}$ sensitization of contractile elements in rat proximal and distal colon. Br J Pharmacol 2004;142:657-666.

87. Ayman S, Wallace P, Wayman CP, Gibson A, McFadzean I. Receptorindependent activation of Rho-kinase-mediated calcium sensitisation in smooth muscle. Br J Pharmacol 2003;139:1532-1538.

88. Teixeira CE, Jin L, Ying Z, Palmer T, Webb RC. $\mathrm{Ca}^{2+}$ sensitization and the regulation of contractility in rat anococcygeus and retractor penis muscle. Biochem Pharmacol 2005;69:1483-1492.

89. Bhetwal BP, An C, Baker SA, Lyon KL, Perrino BA. Impaired contractile responses and altered expression and phosphorylation of $\mathrm{Ca}^{2+}$ sensitization proteins in gastric antrum smooth muscles from $o b / o b$ mice. $\mathrm{J}$ Muscle Res Cell Motil 2013;34:137-149.

90. Otto B, Steusloff A, Just I, Aktories K, Pfitzer G. Role of Rho proteins 
in carbachol-induced contractions in intact and permeabilized guineapig intestinal smooth muscle. J Physiol 1996;496(Pt 2):317-329.

91. Sward K, Dreja K, Susnjar M, Hellstrand P, Hartshorne DJ, Walsh MP. Inhibition of Rho-associated kinase blocks agonist-induced $\mathrm{Ca}^{2+}$ sensitization of myosin phosphorylation and force in guinea-pig ileum. J Physiol 2000;522:33-49.

92. Mori D, Hori M, Murata T, et al. Synchronous phosphorylation of CPI-17 and MYPT1 is essential for inducing $\mathrm{Ca}^{2+}$ sensitization in intestinal smooth muscle. Neurogastroenterol Motil 2011;23:1111-1122.

93. Ohama T, Hori M, Momotani E, et al. Intestinal inflammation downregulates smooth muscle CPI-17 through induction of TNF-alpha and causes motility disorders. Am J Physiol Gastrointest Liver Physiol 2007;292:G1429-G1438.

94. Sato K, Ohkura S, Kitahara Y, et al. Involvement of CPI-17 downregulation in the dysmotility of the colon from dextran sodium sulphateinduced experimental colitis in a mouse model. Neurogastroenterol Motil 2007;19:504-514.

95. Rattan S, Singh J. RhoA/ROCK pathway is the major molecular determinant of basal tone in intact human internal anal sphincter. Am J Physiol Gastrointest Liver Physiol 2012;302:G664-G675.

96. Patel CA, Rattan S. Cellular regulation of basal tone in internal anal sphincter smooth muscle by RhoA/ROCK. Am J Physiol Gastrointest Liver Physiol 2007;292:G1747-G1756.

97. Chakder S, Sarma DNK, Rattan S. Mechanism of internal anal sphincter smooth muscle relaxation by phorbol 12,13-dibutyrate. Am J Physiol Gastrointest Liver Physiol 2001;280:G1341-G1350.

98. Huang J, Zhou H, Mahavadi S, Sriwai W, Lyall V, Murthy KS. Signaling pathways mediating gastrointestinal smooth muscle contraction and MLC20 phosphorylation by motilin receptors. Am J Physiol Gastrointest Liver Physiol 2005;288:G23-G31.

99. Sriwai W, Mahavadi S, Al-Shboul O, Grider JR, Murthy KS. Distinctive $G$ protein-dependent signaling by protease-activated receptor 2 (PAR2) in smooth muscle: Feedback inhibition of RhoA by cAMPindependent PKA. PLoS One 2013;8:e66743.

100. Gonzalez-Montelongo MC, Marin R, Gomez T, Marrero-Alonso J, Diaz M. Androgens induce nongenomic stimulation of colonic contractile activity through induction of calcium sensitization and phosphorylation of LC20 and CPI-17. Mol Endocrinol 2010;24:1007-1023.

101. Rattan S, Puri RN, Fan YP. Involvement of Rho and Rho-Associated kinase in sphincteric smooth muscle contraction by angiotensin II. Exp Biol Med 2003;228:972-981.

102. Araki S, Ito M, Kureishi $\mathrm{Y}$, et al. Arachidonic acid-induced $\mathrm{Ca}^{2+}$ sensitization of smooth muscle contraction through activation of Rho-kinase. Pflügers Archive 2001;441:596-603.

103. Rattan S, Singh J, Kumar S, Phillips B. Nature of extracellular signal that triggers RhoA/ROCK activation for the basal internal anal sphincter tone in humans. Am J Physiol Gastrointest Liver Physiol 2015;308:G924-G933.

104. Weber LP, Van Lierop JE, Walsh MP. $\mathrm{Ca}^{2+}$-independent phosphorylation of myosin in rat caudal artery and chicken gizzard myofilaments. J Physiol 1999;516(Pt 3):805-824.

105. Ihara E, Moffat L, Ostrander J, Walsh MP, MacDonald JA. Charac- terization of protein kinase pathways responsible for $\mathrm{Ca}^{2+}$ sensitization in rat ileal longitudinal smooth muscle. Am J Physiol Gastrointest Liver Physiol 2007;293:G699-G710.

106. Amano M, Ito M, Kimura K, et al. Phosphorylation and activation of myosin by Rho-associated kinase (Rho-kinase). J Biol Chem 1996;271:20246-20249.

107. Ikebe M, Hartshorne DJ, Elzinga M. Phosphorylation of the 20,000-dalton light chain of smooth muscle myosin by the calciumactivated, phospholipid-dependent protein kinase. Phosphorylation sites and effects of phosphorylation. J Biol Chem 1987;262:9569-9573.

108. Komatsu S, Hosoya H. Phosphorylation by MAPKAP kinase 2 activates $\mathrm{Mg}^{2+}$-ATPase activity of myosin II. Biochem Biophys Res Comm 1996;223:741-745.

109. Murata-Hori M, Fukuta Y, Ueda K, Iwasaka T, Hosoya H. HeLa ZIP kinase induces diphosphorylation of myosin II regulatory light chain and reorganization of actin filaments in nonmuscle cells. Oncogene 2001;57:8175-8183.

110. Niiro N, Ikebe M. Zipper-interacting protein kinase induces $\mathrm{Ca}^{2+}$-free smooth muscle contraction via myosin light chain phosphorylation. J Biol Chem 2001;276:29567-29574.

111. Suizu F, Ueda K, Iwasaki T, Murata-Hori M, Hosoya H. Activation of actin-activated MgATPase activity of myosin II by phosphorylation with MAPK-activated protein kinase-1b (RSK-2). J Biochem 2000;128:435440.

112. Wilson D, Sutherland C, Borman M, Deng J, MacDonald J, Walsh $\mathrm{M}$. Integrin-linked kinase is responsible for $\mathrm{Ca}^{2+}$-independent myosin diphosphorylation and contraction of vascular smooth muscle. Biochem J 2005;392(Pt 2):641-648.

113. Ihara E, Yu Q, Chappellaz M, Macdonald JA. ERK and p38MAPK pathways regulate myosin light chain phosphatase and contribute to $\mathrm{Ca}^{2+}$ sensitization of intestinal smooth muscle contraction. Neurogastroenterol Motil 2015;27:135-146.

114. Welsh C, Kasirer MY, Pan J, Shifrin Y, Belik J. Pantoprazole decreases gastroesophageal muscle tone in newborn rats via rho-kinase inhibition. Am J Physiol Gastrointest Liver Physiol 2014;307:G390-G396.

115. Singh J, Maxwell PJ 4th, Rattan S. Immunocytochemical evidence for PDBu-induced activation of RhoA/ROCK in human internal anal sphincter smooth muscle cells. Am J Physiol Gastrointest Liver Physiol 2011;301:G317-G325.

116. Hersch E, Huang J, Grider JR, Murthy KS. Gq/G13 signaling by ET-1 in smooth muscle: MYPT1 phosphorylation via ETA and CPI17 dephosphorylation via ETB. Am J Physiol Cell Physiol 2004;287: C1209-C1218.

117. Ohama T, Hori M, Sato K, Ozaki H, Karaki H. Chronic Treatment with interleukin- $1 \mathrm{~b}$ attenuates contractions by decreasing the activities of CPI-17 and MYPT-1 in intestinal smooth muscle. J Biol Chem 2003; 278:48794-48804.

118. Ohama T, Hori M, Fujisawa M, et al. Downregulation of CPI-17 contributes to dysfunctional motility in chronic intestinal inflammation model mice and ulcerative colitis patients. J Gastroenterol 2008;43:858865.

119. Shimomura A, Ohama T, Hori M, Ozaki H. 17Beta-estradiol induces 
gastrointestinal motility disorder by decreasing CPI-17 phosphorylation via changes in Rho-family G-protein Rnd expression in small intestine. J Vet Med Sci 2009;71:1591-1597.

120. Murthy KS. Signal transduction in gastrointestinal smooth muscle. Cell Sig 1997;9:269-276.

121. Alvarez SM, Miner AS, Browne BM, Ratz PH. Failure of Bay K 8644 to induce RhoA kinase-dependent calcium sensitization in rabbit blood vessels. Br J Pharmacol 2010;160:1326-1337.

122. MacDonald JA, Borman MA, Murínyi A, Somlyo AV, Hartshorne DJ, Haystead TA. Identification of the endogenous smooth muscle myosin phosphatase-associated kinase. Proc Natl Acad Sci 2001;98:2419-2424.

123. Muranyi A, Derkach D, Erdodi F, Kiss A, Ito M, Hartshorne DJ. Phosphorylation of Thr695 and Thr850 on the myosin phosphatase target subunit: inhibitory effects and occurrence in A7r5 cells. FEBS Lett 2005;579:6611-6615.

124. Muranyi A, MacDonald JA, Deng JT, et al. Phosphorylation of the myosin phosphatase target subunit by integrin-linked kinase. Biochem J
2002;366(Pt 1):211-216.

125. Sathishkumar K, Yallampalli U, Elkins R, Yallampalli C. Raf-1 kinase regulates smooth muscle contraction in the rat mesenteric arteries. J Vascular Res 2010;47:384-398

126. Sanders KM, Ward SM, Koh SD. Interstitial cells: Regulators of smooth muscle function. Physiol Rev 2014;94:859-907.

127. Sanders KM, Hwang SJ, Ward SM. Neuroeffector apparatus in gastrointestinal smooth muscle organs. J Physiol 2010;588(Pt 23):4621-4639.

128. Sanders KM, Koh SD, Ro S, Ward SM. Regulation of gastrointestinal motility-insights from smooth muscle biology. Nat Rev Gastroenterol Hepatol 2012;9:633-645.

129. Ward SM, Burns AJ, Torihashi S, Sanders KM. Mutation of the protooncogene c-kit blocks development of interstitial cells and electrical rhythmicity in murine intestine. J Physiol 1994;480(Pt 1):91-97.

130. Tsai MH, Kamm KE, Stull JT. Signalling to contractile proteins by muscarinic and purinergic pathways in neurally stimulated bladder smooth muscle. J Physiol 2012;590:5107-5121. 